\title{
The myristoylated amino-terminus of an Arabidopsis calcium- dependent protein kinase mediates plasma membrane localization
}

\author{
Sheen X. Lu • Estelle M. Hrabak
}

Received: 16 July 2012/ Accepted: 15 April 2013/Published online: 23 April 2013

(c) The Author(s) 2013. This article is published with open access at Springerlink.com

\begin{abstract}
Calcium-dependent protein kinases (CDPK) are a major group of calcium-stimulated kinases found in plants and some protists. Many CDPKs are membraneassociated, presumably because of lipid modifications at their amino termini. We investigated the subcellular location and myristoylation of AtCPK5, a member of the Arabidopsis CDPK family. Most AtCPK5 was associated with the plasma membrane as demonstrated by two-phase fractionation of plant microsomes and by in vivo detection of AtCPK5-GFP fusion proteins. AtCPK5 was a substrate for plant $N$-myristoyltransferase and myristoylation was prevented by converting the glycine at the proposed site of myristate attachment to alanine (G2A). In transgenic plants, a G2A mutation completely abolished AtCPK5 membrane association, indicating that myristoylation was essential for membrane binding. The first sixteen amino acids of AtCPK5 were sufficient to direct plasma membrane localization. In addition, differentially phosphorylated forms of AtCPK5 were detected both in planta and after expression of AtCPK5 in a cell-free plant extract. Our results demonstrate that AtCPK5 is myristoylated at its amino terminus and that myristoylation is required for membrane binding.
\end{abstract}

Keywords Myristoylation - Acylation - Calcium · Kinase $\cdot$ Membrane targeting $\cdot$ Subcellular localization

S. X. Lu · E. M. Hrabak $(\bowtie)$

Department of Molecular, Cellular \& Biomedical Sciences, University of New Hampshire, Durham, NH 03824, USA

e-mail: estelle.hrabak@unh.edu

Present Address:

S. X. Lu

Department of Molecular, Cellular and Developmental Biology,

University of California, Los Angeles, CA 09905, USA

\section{Introduction}

Calcium is a ubiquitous signaling molecule in plants (Hashimoto and Kudla 2011). Transient cytosolic calcium signals are generated in response to environmental signals or stresses such as light, cold, pathogens, or drought, as well as in response to internal stimuli, and these signals are decoded by various calcium-binding proteins (DeFalco et al. 2010). Since calcium has limited diffusion potential in the cytosol (Allbritton et al. 1992), rapid and efficient calcium detection occurs when calcium sensor proteins are located at cell membranes in close proximity to sites of calcium influx.

Proteins in the calcium-dependent protein kinase (CDPK) family have characteristics that enable them to be effective transducers of cytosolic calcium fluxes. All CDPKs have a typical serine/threonine kinase catalytic domain fused via a regulatory autoinhibitory domain to a calmodulin-like domain that directly binds calcium (Cheng et al. 2002; Hrabak et al. 2003; Mehlmer et al. 2010). Calcium binding to the calmodulin-like domain induces intramolecular conformational changes that lead to rapid and calcium-specific activation of the catalytic domain (Huang et al. 1996). CDPKs also contain a highly divergent amino-terminal variable domain that is critical for correct subcellular localization of the enzyme (Martin and Busconi 2000; Lu and Hrabak 2002; Dammann et al. 2003; Raices et al. 2003; Chehab et al. 2004; Gargantini et al. 2006) and may also play a role in substrate recognition (Ito et al. 2010).

Although not found in metazoans, CDPKs have been identified in all plants examined to date, including mosses, liverworts, green algae, gymnosperms and angiosperms, and are also found in the apicomplexan protists (Zhang and Choi 2001). Most plants encode multiple CDPK isoforms. For example, 34 genes encoding CDPKs have been 
identified in the Arabidopsis thaliana genome (Hrabak et al. 2003), while there are 29 in rice (Asano et al. 2005) and at least 21 in Medicago truncatula (Gargantini et al. 2006). CDPK isoforms may vary in substrate specificity, enzyme kinetics, expression pattern, or subcellular location (Hrabak et al. 2003; Harper et al. 2004) and are involved in processes such as carbon and nitrogen metabolism (Douglas et al. 1998; Asano et al. 2002), plant growth and development (Ivashuta et al. 2005; Gargantini et al. 2006; Yoon et al. 2006), defense against pathogens (Romeis et al. 2001; Freymark et al. 2007; Kobayashi et al. 2007), and responses to hormones and abiotic stresses (Abbasi et al. 2004; Ludwig et al. 2005; Szczegielniak et al. 2005; Ma and Wu 2007; Zhu et al. 2007; Franz et al. 2011).

Many CDPKs are membrane associated although they do not contain recognizable transmembrane domains. In Arabidopsis, 10 of the 34 CDPKs have been localized to the plasma membrane, peroxisome, or endoplasmic reticulum, while two are predominantly cytosolic ( $\mathrm{Lu}$ and Hrabak 2002; Dammann et al. 2003; Rodriguez Milla et al. 2006; Zhu et al. 2007; Coca and San Segundo 2010; Mehlmer et al. 2010). Membrane binding of CDPKs is likely mediated by acylation of the amino-terminal variable domain. Myristoylation was first demonstrated for a zucchini CDPK (Ellard-Ivey et al. 1999) and has subsequently been reported for CDPKs from other species. In Arabidopsis, the variable domain of AtCPK2 is myristoylated and this modification is required for membrane association ( $\mathrm{Lu}$ and Hrabak 2002). Similar results have been reported for CDPKs from rice (Martin and Busconi 2000), ice plant (Chehab et al. 2004), potato (Raices et al. 2001; Raices et al. 2003), and tomato (Rutschmann et al. 2002).

Many myristoylated proteins are known or are predicted to be involved in cellular signaling pathways (Boisson et al. 2003; Maurer-Stroh et al. 2004; Resh 2004), and myristoylation is often required for correct protein function. For example, in Arabidopsis, myristoylation of the SOS3 calcium-binding protein is required for salt tolerance (Ishitani et al. 2000), BON1/CPN1 myristoylation is required for normal plant growth ( $\mathrm{Li}$ et al. 2010), and SnRK1 myristoylation affects the catalytic activity of this kinase and its role in shoot meristem development (Pierre et al. 2007).

Protein myristoylation is catalyzed by myristoylCoA:protein $N$-myristoyltransferase (NMT; Rajala et al. 2000; Farazi et al. 2001). Following removal of the initiator methionine, NMT catalyzes the formation of a stable amide bond between myristate (C14:0) and the exposed aminoterminal glycine (Gly-2) residue of a substrate protein. In addition to an absolute requirement for Gly-2, the amino acids immediately following Gly-2 play critical roles in determining whether a protein can be a substrate for NMT (Towler et al. 1988; Rocque et al. 1993; Utsumi et al. 2004).
Computer algorithms developed to predict protein myristoylation (Maurer-Stroh et al. 2002b; Bologna et al. 2004; Podell and Gribskov 2004) indicate that many CDPKs have putative $N$-myristoylation sites at their amino termini.

In this study, we investigate protein modifications and subcellular location of a CDPK from Arabidopsis thaliana, AtCPK5. We demonstrate that AtCPK5 is myristoylated in vitro, although this was not predicted by all of the available myristoylation programs, and that the majority of the AtCPK5 protein in plant cells is associated with the plasma membrane. We also present evidence that phosphorylation of AtCPK5 occurs in plant extracts. Mutation of Gly-2 prevents myristoylation and abolishes membrane association of AtCPK5 in plants. Finally, we demonstrate that the first 16 amino acids of AtCPK5 are sufficient to direct plasma membrane targeting.

\section{Experimental procedures}

\section{Plasmid constructs}

The pCPK5-16aa-GUS construct contained a 1,417 bp genomic DNA fragment followed in-frame by the $\beta$-glucuronidase (GUS) coding sequence from the E. coli uidA gene and the nos terminator. The 1,417 bp Arabidopsis genomic DNA fragment (Arabidopsis gene At4g35310) consisted of 50 nucleotides of coding sequence preceded by the 449 bp CPK5 untranslated leader (containing a $224 \mathrm{bp}$ intron) and $918 \mathrm{bp}$ of non-transcribed sequence, presumed to contain the promoter region. The GUS coding sequence and the nos terminator were from pBI101 (Clontech, Mountain View, CA, USA). For plant transformation, this entire region was cloned into pBIN19 (Bevan 1984) to create pCPK5-16aa-GUS. The first 16 amino acids of AtCPK5 are MGNSCRGSFKDKLDEG. Mutagenesis of the glycine codon (GGC) at position 2 to alanine (GCC) was performed with the QuikChange SiteDirected Mutagenesis kit (Stratagene, La Jolla, CA, USA) according to the manufacturer's instructions to create pCPK5-G2A-GUS. The presence of the G2A mutation was confirmed by DNA sequencing. For constructs pCPK516aa-GFP and pCPK5-G2A-GFP, the GUS coding sequence in pCPK5-16aa-GUS and pCPK5-G2A-GUS was replaced with the coding sequence for soluble-modified red-shifted green fluorescent protein (smRS-GFP, Davis and Vierstra 1998).

Plant transformation and growth conditions

Arabidopsis thaliana (ecotype Columbia) plants were transformed by the floral dip method (Clough and Bent 1998) and transgenics were selected on solidified 
Murashige and Skoog basal medium with Gamborg's B-5 vitamins (Sigma, St. Louis, MO, USA) and $0.1 \%(\mathrm{w} / \mathrm{v})$ sucrose, pH 5.7, containing $50 \mathrm{mg} / \mathrm{L}$ kanamycin. Kanamycin-resistant plants were confirmed to contain the transgene using a rapid PCR method (Klimyuk et al. 1993).

Membrane isolation and aqueous two-phase partitioning

Seeds from transgenic plants were surface-sterilized and grown in liquid Murashige and Skoog basal medium with Gamborg's B-5 vitamins and $1 \%(\mathrm{w} / \mathrm{v})$ sucrose, $\mathrm{pH} 5.7$, at $21{ }^{\circ} \mathrm{C}$ with an $18 \mathrm{~h}$ photoperiod. Aeration was maintained on a rotary shaker at $120 \mathrm{rpm}$. Microsomal membranes were prepared using a modification of a previously described procedure (Schaller and DeWitt 1995). All homogenization and fractionation steps were conducted on ice or in a cold room with prechilled buffers and equipment. All buffers contained protease inhibitor cocktail (Roche, Indianapolis, IN, USA). Two-week-old plants were ground in homogenization buffer $(50 \mathrm{mM}$ Tris- $\mathrm{HCl}$, $\mathrm{pH} 8.2,20 \%$ [v/v] glycerol, $2 \mathrm{mM}$ EDTA; $1 \mathrm{ml} / \mathrm{g}$ fresh weight) with a mortar and pestle. The homogenates were cleared by filtration through Miracloth (Calbiochem, La Jolla, CA, USA) followed by centrifugation at $5,000 \times g$ for $5 \mathrm{~min}$. Microsomal membranes were isolated by centrifugation of the supernatant for $30 \mathrm{~min}$ at $125,000 \times \mathrm{g}$. Membrane pellets were resuspended in SPK buffer $(0.33 \mathrm{M}$ sucrose, $5 \mathrm{mM} \mathrm{KPO}_{4}$, and $3 \mathrm{mM} \mathrm{KCl,} \mathrm{pH} \mathrm{7.8)} \mathrm{using} \mathrm{a}$ ground glass homogenizer. Aqueous two-phase partitioning to enrich for plasma membrane vesicles was conducted essentially as described (Larsson et al. 1987). Resuspended microsomes were added to a $6.3 \%$ (w/w) DextranT500/ PEG3350 phase mixture prepared in SPK buffer and the phases were separated at $1,000 \times g$ for 5-10 min. Both upper and lower phases were repartitioned twice with fresh lower or upper phase, respectively. The final upper and lower phases were diluted separately in $10 \mathrm{mM}$ Tris- $\mathrm{HCl}$ (pH 7.0) containing $1 \mathrm{mM}$ EDTA and $1 \mathrm{mM}$ EGTA. Phase-partitioned membranes were collected by centrifugation at $125,000 \times g$ for $30 \mathrm{~min}$ and resuspended in equal volumes of SPK buffer.

\section{AtCPK5 antibodies}

AtCPK5 rabbit polyclonal antiserum was raised against a fusion protein containing the first 50 amino acids of AtCPK5 fused to the carboxyl terminus of glutathione S-transferase. The construct was made in pGEX-KT (Hakes and Dixon 1992). Recombinant protein expressed in $E$. coli was purified on a glutathione-agarose matrix (Amersham Bioscience, Piscataway, NJ, USA) and injected into female New Zealand White rabbits. Crude serum was precipitated with $50 \%$ ammonium sulfate and redissolved in phosphate-buffered saline (PBS) $[137 \mathrm{mM} \mathrm{NaCl}$, $4.3 \mathrm{mM} \mathrm{Na}{ }_{2} \mathrm{HPO}_{4} .7 \mathrm{H}_{2} \mathrm{O}, 1.5 \mathrm{mM} \mathrm{KH}{ }_{2} \mathrm{PO}_{4} 2.7 \mathrm{mM} \mathrm{KCl}$. An affinity matrix for purifying AtCPK5 antibodies was prepared by cloning the AtCPK5 cDNA into pRSET-A (Invitrogen, Carlsbad, CA, USA), purifying the expressed proteins on His-Select nickel affinity gel (Sigma), and crosslinking the purified AtCPK5-6His to Affi-Gel 15 (BioRad Laboratories, Hercules, CA, USA). After binding of the partially purified antibody to this matrix, AtCPK5specific antibodies were eluted with $0.1 \mathrm{M}$ glycine $(\mathrm{pH} 2.7$ ) and immediately neutralized with 0.1 volume of 1 M Tris$\mathrm{HCl}$ ( $\mathrm{pH}$ 8.0), followed by dialysis against PBS. Antibody was used at a 1000-fold dilution.

Immunoblot analysis

For SDS-PAGE, samples were mixed with $3 \times$ Blue Loading Buffer (New England Biolabs, Beverly, MA, USA) and incubated at $37^{\circ} \mathrm{C}$ for $30 \mathrm{~min}$. After electrophoresis at $4{ }^{\circ} \mathrm{C}$, proteins were electroblotted to PVDF membrane (Millipore, Bedford, MA, USA) and immunodetection was performed as described previously ( $\mathrm{Lu}$ and Hrabak 2002). Antibodies for detection of specific membranes were: anti-H ${ }^{+}$-ATPase (DeWitt and Sussman 1995) for plasma membrane $(1: 10,000)$, anti-BiP (Hofte et al. 1992) for endoplasmic reticulum $(1: 1,000)$, and anti- $\beta$ ATPase D (Luethy et al. 1993) for mitochondrial membranes (1:100). Membranes were stripped between detections following the manufacturer's instructions. Thylakoid membranes were identified by spectrophotometric detection of chlorophyll a and b (Lichtenthaler 1987).

In vitro myristoylation assay

AtCPK5 cDNA was inserted into pBluescript II $\mathrm{KS}$ (Stratagene) and expressed under control of the vector's T7 promoter. The transcript produced from this clone contains $38 \mathrm{bp}$ of sequence from the vector and $18 \mathrm{bp}$ of the AtCPK5 leader preceding the AtCPK5 translation initiation codon. There is no alternate start codon in the upstream sequence. Myristoylation assays were performed with the TnT Coupled Transcription/Translation Wheat Germ Extract System (Promega Corp., Madison, WI, USA) according to the manufacturer's instructions. cDNAs encoding either wildtype or mutant AtCPK5 proteins were in vitro transcribed and translated in the presence of either $10 \mu \mathrm{Ci}$ of $\mathrm{L}-\left[{ }^{35} \mathrm{~S}\right]$-methionine $(1,000 \mathrm{Ci} / \mathrm{mmol}$; Amersham) or $50 \mu \mathrm{Ci}$ of $\left[9,10-{ }^{3} \mathrm{H}\right]$-myristic acid $(54 \mathrm{Ci} / \mathrm{mmol}$; Amersham Bioscience). Before use, the myristic acid was dried under nitrogen and resuspended by vortexing in DEPC-treated water at a concentration of $10 \mu \mathrm{Ci} / \mu \mathrm{l}$. Control reactions contained no plasmid. After $90 \mathrm{~min}$ 
incubation at $30{ }^{\circ} \mathrm{C}$, reaction products were separated by SDS-PAGE and analyzed by fluorography with Entensify Universal Autoradiography Enhancer (PerkinElmer, Shelton, CT, USA).

\section{Dephosphorylation assay}

Products from in vitro myristoylation assays $(10 \mu \mathrm{l})$ or the upper phase from two phase partitioning $(10 \mu \mathrm{l})$ were incubated with 5 units of calf intestinal alkaline phosphatase (Roche) for $15 \mathrm{~min}$ at $30{ }^{\circ} \mathrm{C}$. Control reactions contained phosphatase inhibitor cocktail II (Sigma). The reactions were subsequently boiled in the presence of $3 \times$ Blue Loading Buffer, separated by SDS-PAGE, and AtCPK5 was visualized by immunoblotting.

\section{$\beta$-Glucuronidase assays}

$\beta$-Glucuronidase (GUS) activity was determined with a fluorometric assay (Gallagher 1992). For CPK5-16aa-GUS plants, total membrane-bound GUS activity (measured in nmol $\mathrm{min}^{-1} \mathrm{mg}^{-1}$ ) ranged from $1.1 \times 10^{4}$ to $1.8 \times 10^{4}$ $(n=7)$, while GUS activity from CPK5-G2A-GUS plants ranged from $1.0 \times 10^{3}$ to $2.4 \times 10^{3}(n=6)$.

Transient expression of AtCPK5-GFP fusion proteins

p35SBSYFP (Katiyar-Agarwal et al. 2006), pCPK5-16aaGFP, or pCPK5-G2A-GFP were purified using a QIAprep Spin Miniprep Kit (Qiagen Inc., Valencia, CA, USA). Rosette leaves $(0.8-1.2 \mathrm{~cm}$ in length) were collected from 3- to 4-week-old Arabidopsis plants and bombarded with $0.8 \mu \mathrm{g}$ plasmid DNA coated on $480 \mathrm{ug}$ of gold particles $(1 \mu \mathrm{m}$; Sigma) using a PDS-1000/He delivery system (BioRad). The distance between the stop screen and the leaves was $\sim 9 \mathrm{~cm}$ and a helium pressure of 650 psi was employed. Bombarded leaves were incubated in water at room temperature for 4-5 h. Images were collected using a SP2 confocal microscope (Leica Microsystems, Inc., Bannockburn, IL, USA), analyzed using MetaMorph 4.5 software (Universal Imaging Corp., Downingtown, PA, USA), and processed with Photoshop (Adobe Systems Inc., San Jose, CA, USA).

\section{Results}

AtCPK5 is associated with the plasma membrane

Several Arabidopsis CDPKs are known to be membrane bound (Lu and Hrabak 2002; Dammann et al. 2003; Choi et al. 2005; Coca and San Segundo 2010; Mehlmer et al.
2010) although AtCPK5 has not been studied previously. To determine whether AtCPK5 was associated with the plasma membrane or with intracellular membranes, aqueous two-phase partitioning was used to fractionate microsomes from wildtype plants. This technique enriches plasma membrane vesicles in the upper phase while other intracellular membranes partition to the lower phase (Larsson et al. 1987). After phase separation, both phases were analyzed by immunoblotting to detect AtCPK5 protein and protein markers for specific membranes (Fig. 1). AtCPK5 was highly enriched in the upper phase, similar to the $\mathrm{H}^{+}$-ATPase plasma membrane marker. As expected, intracellular membrane marker proteins were enriched in the lower phase. These results indicate that AtCPK5 is associated with the plasma membrane but does not exclude the possibility that some AtCPK5 protein may be located in the cytosol.

AtCPK5 is myristoylated in vitro

To investigate whether the amino terminus of AtCPK5 contains a myristoylation consensus sequence, two myristoylation prediction programs were queried: Myristoylator (http://us.expasy.org/tools/myristoylator/myristoylator-ref. html; Bologna et al. 2004) and NMT Predictor (http:// mendel.imp.ac.at/myriatate/SUPLpredictor.htm; MaurerStroh et al. 2002a). Myristoylator predicted myristoylation

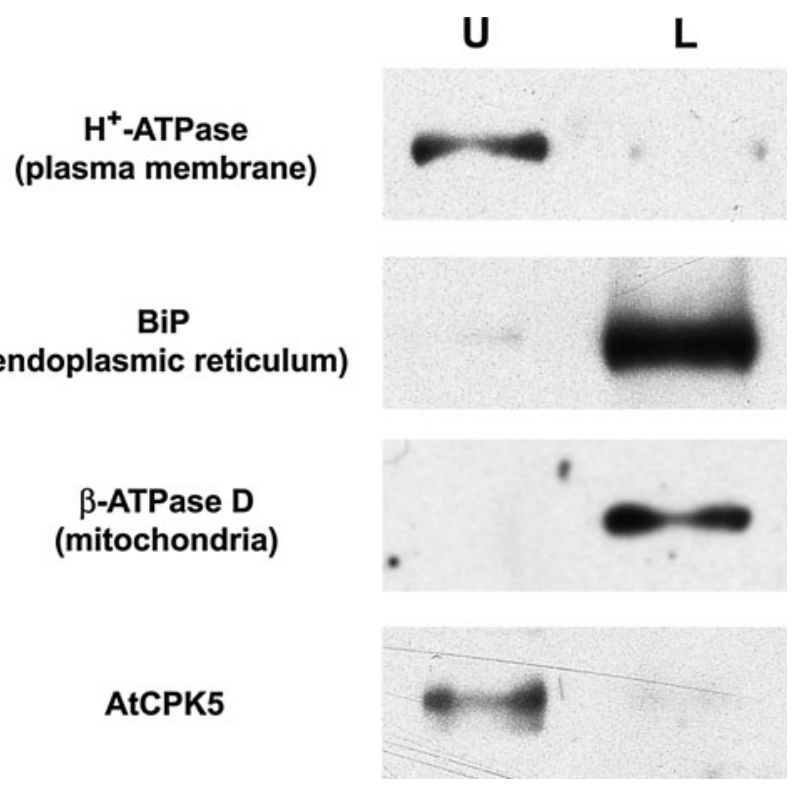

Fig. 1 AtCPK5 is localized to the plasma membrane. Membranes from wildtype Arabidopsis plants were fractionated by aqueous twophase partitioning. Equal proportions of the upper and lower phases were separated by SDS-PAGE, transferred to PVDF membranes, and analyzed sequentially using antibodies specific for AtCPK5 and for membrane marker proteins. $U$ upper phase (enriched for plasma membrane); $L$ lower phase (enriched for intracellular membranes) 
of AtCPK5 while NMT Predictor did not. To determine whether AtCPK5 could be myristoylated in vitro, we used a cell-free transcription/translation system from wheat germ that is known to contain NMT activity (Ellard-Ivey et al. 1999; Lu and Hrabak 2002). Both wildtype AtCPK5 protein and its glycine-2 to alanine (G2A) mutant were tested. Reactions included either $\left[{ }^{35} \mathrm{~S}\right]$-methionine for detection of total protein synthesis or $\left[{ }^{3} \mathrm{H}\right]$-myristic acid for detection of myristoylated proteins. For both DNA templates, the major product of the $\left[{ }^{35} \mathrm{~S}\right]$-methioninelabeled reaction was a protein doublet near the predicted mass of $62.1 \mathrm{kDa}$ (Fig. 2a). [ $\left.{ }^{3} \mathrm{H}\right]$-myristate was incorporated into a $62 \mathrm{kDa}$ product when the wildtype AtCPK5 protein was expressed but not when template DNA containing the G2A mutation was used (Fig. 2b). The identity of these radiolabeled proteins as AtCPK5 was confirmed by immunoblot analysis with AtCPK5 antibody, which recognizes the unique amino terminus of AtCPK5 (Fig. 2c). The $50 \mathrm{kDa}$ protein recognized by the AtCPK5 antibodies represents non-specific binding to a wheat germ protein since it was present in a control reaction that contained no DNA template (Fig. 2c, lane 1). The smaller, non-myristoylated proteins routinely observed in $\left[{ }^{35} \mathrm{~S}\right]$ methionine-labeled reactions may be alternative translation products from the AtCPK5 constructs or AtCPK5 degradation products (Fig. 2a). These results indicate that the AtCPK5 protein can be myristoylated in vitro and that Gly-2 is essential for myristoylation.

AtCPK5 is phosphorylated in plants and in wheat germ extract

We noticed that AtCPK5 was often detected as a doublet of approximately 60 and $62 \mathrm{kDa}$ whether the protein source was Arabidopsis plant extracts (Fig. 1) or wheat germ expression extracts (Fig. 2). This doublet was observed for both wildtype AtCPK5 and the G2A mutant protein, indicating that the second band is not due to the effects of myristoylation. Phosphorylation can retard the migration of proteins, so we examined whether the $62 \mathrm{kDa}$ species represented a phosphorylated form of AtCPK5. Three different protein samples were tested: (1) the upper phase after aqueous two-phase partitioning of wildtype plant extracts, (2) wheat germ transcription/translation reactions expressing wildtype AtCPK5, or (3) wheat germ transcription/translation reactions expressing the G2A-mutated AtCPK5. Protein samples were treated with alkaline phosphatase in the presence or absence of alkaline phosphatase inhibitor. Alkaline phosphatase treatment resulted in the disappearance of the $62 \mathrm{kDa}$ species (Fig. 3) and an increase in abundance of the $60 \mathrm{kDa}$ species. In the presence of both alkaline phosphatase and alkaline phosphatase

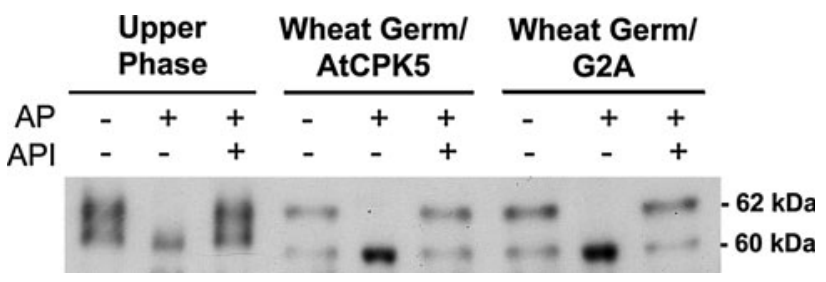

Fig. 3 AtCPK5 is phosphorylated when expressed in planta or in vitro. The upper phase from two-phase partitioning of Arabidopsis membranes (left), cell-free wheat germ extract following in vitro expression of AtCPK5 (center), or cell-free wheat germ extract following expression of the AtCPK5-G2A mutant protein (right) were incubated with calf intestinal alkaline phosphatase (AP) and alkaline phosphatase inhibitor (API). The reaction products were separated by SDS-PAGE and AtCPK5 was detected by immunoblotting with AtCPK5 antibody (a)

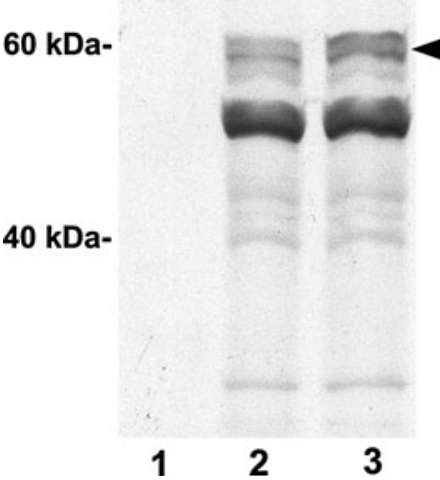

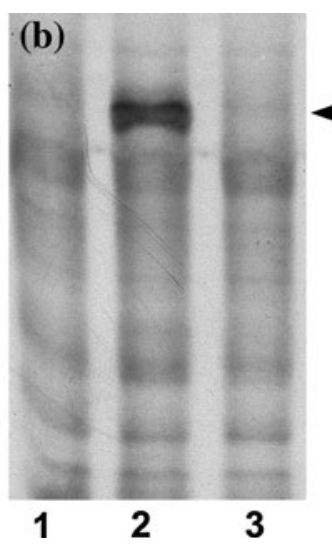

(c)

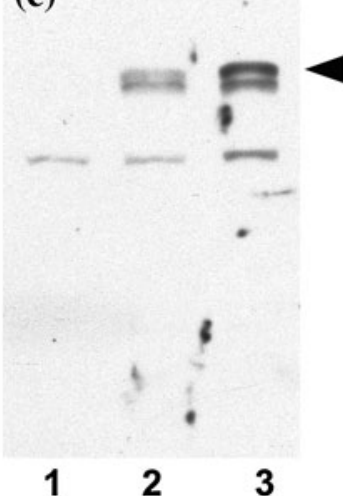

Fig. 2 AtCPK5 is myristoylated in vitro and a G2A mutation prevents myristoylation. In a wheat germ coupled transcription and translation system, AtCPK5 protein (lane 2) was expressed in the presence of either a $\left[{ }^{35} \mathrm{~S}\right]$ methionine; b $\left[{ }^{3} \mathrm{H}\right]$ myristic acid; or c no radiolabel, followed by SDS-PAGE and fluorography (a and b) or immunoblotting (c). Parallel experiments were performed on AtCPK5 protein containing a glycine-2 to alanine mutation (lane 3). Negative control reactions (lane 1) contained no plasmid template for gene expression. Arrows indicate AtCPK5 protein 
inhibitor, both the 60 and $62 \mathrm{kDa}$ species were detected. Slight variations in migration are likely due to differences in buffer composition of the samples. These results indicate that phosphorylated AtCPK5 is present in plant extracts, that phosphorylation also occurs during in vitro synthesis of AtCPK5 in a cell-free extract, and that myristoylation and membrane association are not required for phosphorylation of AtCPK5.

The first 16 amino acids of AtCPK5 are sufficient for plasma membrane localization

Correct subcellular targeting of acylated proteins from metazoans and yeast often requires only a short region at the amino-terminus of the protein (Di Paolo et al. 1997; Gillen et al. 1998; Alsheimer et al. 2000). Previously, we demonstrated that the amino terminus of a different Arabidopsis CDPK, AtCPK2, was sufficient for its correct targeting to the endoplasmic reticulum ( $\mathrm{Lu}$ and Hrabak 2002). To determine whether the amino terminal region of AtCPK5 was sufficient for its membrane targeting, transgenic plants were produced that expressed the first 16 amino acids of AtCPK5 fused to the $\beta$-glucuronidase reporter protein (AtCPK5-16aa-GUS) under control of the native AtCPK5 promoter. For comparison, plants were transformed with the T-DNA from pBI121 in which the GUS protein is expressed from the $35 \mathrm{~S}$ promoter. To determine the relative distribution of GUS protein between cytosol and membranes, plant extracts were centrifuged to separate microsomes from soluble proteins as described previously and GUS activity in these two fractions was measured with a sensitive fluorometric assay. As expected, in control plants transformed with T-DNA from pBI121, the majority of the GUS protein was soluble and only a small amount (2-3\%) was membrane associated, probably due to non-specific membrane binding or trapping of the abundant GUS protein in membrane vesicles during preparation of extracts. In AtCPK5-16aa-GUS plant extracts, the majority $(78 \pm 3 \%)$ of the GUS enzyme activity was in the microsomal fraction, indicating that most of the AtCPK5-GUS fusion protein was membrane associated and that the first 16 amino acids of AtCPK5 are sufficient for membrane targeting.

To determine whether the CPK5-16aa-GUS fusion protein was targeted to the plasma membrane similar to wildtype AtCPK5 (Fig. 1), the microsomal fraction was used for aqueous two-phase partitioning. Both native AtCPK5 protein and the plasma membrane marker were enriched in the upper phase, while the markers for organellar membranes were concentrated in the lower phase (Fig. 4), confirming that the cellular membranes partitioned correctly. The location of the hybrid AtCPK5-16aaGUS fusion protein was determined with a fluorometric assay for GUS activity. The plasma membrane-enriched upper phase contained more GUS activity per milliliter than the lower phase (Fig. 4). When expressed as specific activity to correct for the six-fold greater protein content in the lower phase, the difference between the amount of AtCPK5-16aa-GUS fusion protein in the two phases is apparent. These results indicate that the first 16 amino acids of AtCPK5 are sufficient to correctly target the soluble GUS protein to the plasma membrane.

The G2A mutation abolishes AtCPK5 membrane association in plants

To address the importance of AtCPK5 myristoylation in membrane binding in plants, we examined the effect of mutation of the myristoylation site on membrane association. Site-directed mutagenesis was used to convert the

\section{$\mathrm{H}^{+}$-ATPase (plasma membrane) \\ BiP (endoplasmic reticulum)} $\beta$-ATPase D (mitochondria)

AtCPK5

Chlorophyll (chloroplast) GUS Activity
(CPK5-16aa-GUS)

GUS Specific Activity (CPK5-16aa-GUS)
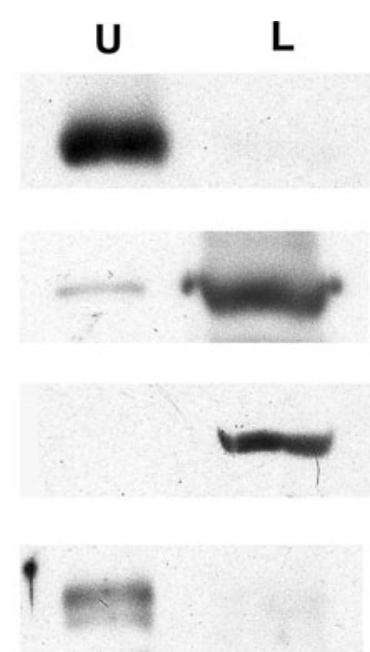

82

2089

473

347

623

85
Fig. 4 The first sixteen amino acids of AtCPK5 are sufficient for plasma membrane localization. Microsomal membranes from CPK516aa-GUS transgenic plants (expressing GUS protein preceded by the first 16 amino acids of AtCPK5) were analyzed by aqueous two-phase partitioning. Equal proportions of the upper and lower phases were separated by SDS-PAGE and assayed by immunoblotting with specific antibodies. Chlorophyll absorbance $(\mathrm{ng} / \mathrm{ml})$ was measured spectrophotometrically. The GUS enzyme was assayed fluorometrically and is expressed as activity $(\mu \mathrm{mol} / \mathrm{min} / \mathrm{ml})$ and as specific activity ( $\mu \mathrm{mol} / \mathrm{min} / \mathrm{mg}$ protein). $U$ upper phase, $L$ lower phase 
second codon of pCPK5-16aa-GUS from glycine to alanine (G2A) to create pCPK5-G2A-GUS. Extracts from transgenic plants expressing the CPK5-G2A-GUS fusion protein were separated into soluble and microsomal fractions by ultracentrifugation. GUS enzyme activity was measured in both fractions using the fluorometric assay. The majority (97\%) of the GUS activity was detected in the soluble fraction, compared with $22 \%$ when plants expressed the CPK5-16aa-GUS transgene without the G2A mutation. These results demonstrate that myristoylation is critical for the membrane binding of AtCPK5 in vivo.

GFP fusions confirm plasma membrane localization of AtCPK5

To confirm the plasma membrane localization of AtCPK5, a construct containing the first 16 amino acids of AtCPK5 fused to green fluorescent protein was used for transient expression in Arabidopsis. pCPK5-16aa-GFP was bombarded into Arabidopsis leaves and expression in epidermal cells was examined by confocal microscopy (Fig. 5). The quantitative GUS assay data presented earlier indicated that $\sim 80 \%$ of AtCPK5 was plasma membrane associated and it is evident from a single optical section near the midpoint of the cell that CPK5-16aa-GFP was found at the cell periphery, corresponding to plasma membrane-localized AtCPK5 (Fig. 5d). A maximum intensity projection indicates that fluorescence was also observed in the cytosol and nucleus, likely corresponding to soluble CPK5-16aa-GFP fusion protein (Fig. 5c). Fluorescence in nuclei was observed routinely for all transgenic plants and was not unexpected since the sizes of free GFP $(26.8 \mathrm{kDa})$ and CPK5-16aa-GFP (28.5 kDa) are below the exclusion limit of the nuclear pore complex (Grebenok et al. 1997). In cells expressing the non-myristoylated CPK5-G2A-GFP fusion protein, fluorescence was localized primarily in the cytosol and nucleus (Fig. 5e, f), in a pattern similar to free GFP (Fig. 5a, b). These data confirm that a substantial proportion of AtCPK5 is localized to the plasma membrane and that the amino-terminal glycine residue is required for membrane binding.

\section{Discussion}

Calcium-dependent protein kinases have been found in all plant genomes and function in many cellular processes, including signaling in response to biotic and abiotic stresses and regulation of carbon and nitrogen metabolism (Klimecka and Muszynska 2007). In this study, we investigated the myristoylation and subcellular localization of AtCPK5 and documented the presence of phosphorylated forms of this enzyme.
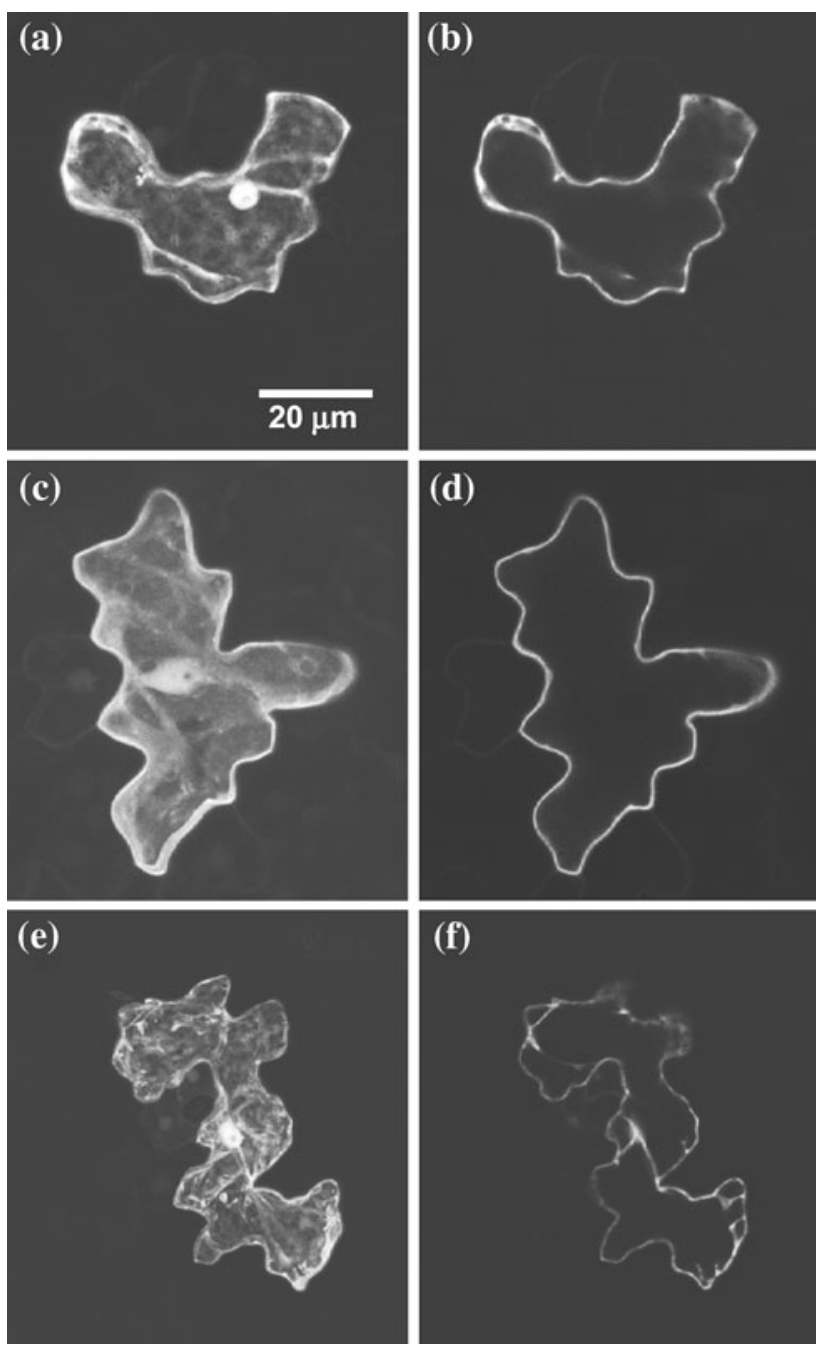

Fig. 5 Plasma membrane localization of AtCPK5 requires glycine-2. Arabidopsis epidermal cells transiently expressing various GFP constructs were observed by confocal microscopy. a and b GFP control; $\mathbf{c}$ and $\mathbf{d}$ CPK5-16aa-GFP; $\mathbf{e}$ and $\mathbf{f}$ CPK5-G2A-GFP. a, $\mathbf{c}$, and e are projections of 10,30 and 26 optical sections, respectively; b, d, and $\mathbf{f}$ are single optical sections

In our experiments, AtCPK5 was routinely detected as a protein doublet on immunoblots using isoform-specific antibodies. The doublet was also apparent in samples containing non-myristoylated AtCPK5 and thus the change in electrophoretic behavior was not attributable to acylation. Phosphorylation can affect protein migration during electrophoresis (Peck 2006) and decreased mobility had previously been documented for a phosphorylated tobacco CDPK (Romeis et al. 2000; Romeis et al. 2001). Treatment of Arabidopsis protein extracts with alkaline phosphatase caused the disappearance of the slower-migrating form of AtCPK5, indicative of phosphorylation. In vitro calcium-dependent autophosphorylation of AtCPK5 had been documented previously (Hrabak et al. 1996) and two autophosphorylated peptides were identified (Hegeman et al. 2006). In these 
experiments, we cannot distinguish autophosphorylation from phosphorylation catalyzed by other kinases present in Arabidopsis or in the wheat germ extract. Some CDPKs, like tobacco NtCDPK2, are phosphorylated at specific sites in a membrane-dependent manner (Witte et al. 2010); however, phosphorylated forms of AtCPK5 were observed for both membrane-bound native AtCPK5 and non-myristoylated AtCPK5-G2A, indicating that phosphorylation was not dependent upon membrane association.

Calcium-dependent protein phosphorylation has been reported previously in plasma membrane-enriched plant cell extracts (Schaller et al. 1992; Verhey et al. 1993; Baizabal-Aguirre and de la Vara 1997; Iwata et al. 1998) and some CDPKs are known to localize to the plasma membrane (Rutschmann et al. 2002; Dammann et al. 2003; Raices et al. 2003; Chehab et al. 2004; Gargantini et al. 2006; Mehlmer et al. 2010; Kobayashi et al. 2012). We began our studies of AtCPK5 localization by fractionating Arabidopsis extracts to separate plasma membranes from intracellular membranes. Both AtCPK5 and a known plasma membrane marker were enriched in the upper fraction while a minor percentage of AtCPK5 was found in the lower cytosolic fraction, indicating that the membranebound AtCPK5 was primarily associated with the plasma membrane. The plasma membrane localization of AtCPK5 could facilitate activation of the enzyme by localized calcium signals generated in response to abiotic or biotic stimuli (reviewed in Kudla et al. 2010). Several plasma membrane-localized proteins, such as the $\mathrm{H}^{+}$-ATPase and several ion channels (Pei et al. 1996; Li et al. 1998; Rutschmann et al. 2002; Mori et al. 2006; Geiger et al. 2010), are phosphorylated in a calcium-dependent manner by CDPKs and represent potential substrates for the membrane-bound form of AtCPK5.

Membrane binding of CDPKs is proposed to be mediated by acylation. This study focused on $N$-myristoylation, an irreversible modification that occurs exclusively at an amino-terminal glycine residue (Rajala et al. 2000). The enzymology and substrate specificity of myristoyltransferases from fungi and animals have been characterized extensively (Towler et al. 1988; Rocque et al. 1993; Johnson et al. 1994; Lodge et al. 1994; Raju et al. 1995; Farazi et al. 2001; Utsumi et al. 2004). Plant $N$-myristoyltransferases are less well understood and differences between the fungal, human and plant enzymes have been noted previously (Rocque et al. 1993; Qi et al. 2000; Boisson et al. 2003; Dumonceaux et al. 2004; Pierre et al. 2007). Algorithms for myristoylation prediction such as NMT Predictor (http://mendel.imp.univie.ac.at/myristate/; Maurer-Stroh et al. 2002a, 2002b) and Myristoylator (http:// us.expasy.org/tools/myristoylator/; Bologna et al. 2004) have been developed primarily using myristoylation data from fungal and animal NMTs. We have found that these algorithms do not always work well for predicting plant myristoylation sites (S. Lu, A. Argyros, and E. Hrabak, unpublished observations). NMT Predictor rejected AtCPK5 (amino terminal sequence: MGNSCRGSF) as an NMT substrate, most likely because of the arginine residue at position 6, which is rarely found in myristoylated proteins from fungi and mammals (Utsumi et al. 2004). Although peptides with arginine- 6 were not myristoylated in vitro in a rabbit reticulocyte lysate (Utsumi et al. 2004), our results using wheat germ lysate clearly demonstrated that AtCPK5 was a bona fide substrate for plant NMT. Boisson et al. (2003) examined the substrate specificity of one of the two Arabidopsis $N$-myristoyltransferases in more detail and concluded that plant NMTs have relaxed substrate specificity compared to other enzymes. Subsequently, a PlantSpecific Myristoylation Predictor (http://plantsp.genomics. purdue.edu/myrist.html) was developed by Podell and Gribskov (2004) using only plant myristoylation data. Because this program was trained using our unpublished results, this website accurately predicts myristoylation of Arabidopsis CDPKs, including AtCPK5.

The majority of known CDPKs, including those from Arabidopsis and rice (Cheng et al. 2002; Hrabak et al. 2003; Ye et al. 2009), contain predicted amino-terminal myristoylation sites, although myristoylation has been demonstrated experimentally for only a small group of CDPKs. Known myristoylated CDPKs are: Arabidopsis AtCPK2, AtCPK3, AtCPK6, AtCPK9, and AtCPK13 (Lu and Hrabak 2002; Boisson et al. 2003; Benetka et al. 2008; Mehlmer et al. 2010), rice OSCPK2 (Martin and Busconi 2000), tomato LeCPK1 (Rutschmann et al. 2002), potato StCDPK1 (Raices et al. 2001), Mesembryanthemum McCPK1(Chehab et al. 2004), and Cucurbita CpCPK1 (Ellard-Ivey et al. 1999). Here, we showed that AtCPK5 is myristoylated on its amino-terminal glycine residue and localized to the plasma membrane. The first 16 amino acids of AtCPK5, which contain the myristoylation consensus sequence, were sufficient to direct plasma membrane targeting of both GUS and GFP. A G2A mutation abolished both myristoylation and in planta membrane association of AtCPK5, demonstrating that myristoylation was absolutely required for membrane binding. Plasma membrane localization has been demonstrated for other CDPKs, including AtCPK9, AtCPK13, LeCPK1, StCDPK1 and StCDPK5 (Rutschmann et al. 2002; Raices et al. 2003; Kobayashi et al. 2012) but other membrane locations are possible. Myristoylated AtCPK2 is targeted to the endoplasmic reticulum (Lu and Hrabak 2002), AtCPK3 is nuclear and perinuclear (Dammann et al. 2003; Mehlmer et al. 2010), and McCPK1 localizes to multiple membranes (Chehab et al. 2004). Thus the amino terminal region of different CDPKs could be used for as targeting signals to direct proteins to specific membranes. 
Myristoylation is unlikely to be the sole determinant of CDPK membrane binding because the hydrophobicity of myristate is not sufficient to maintain long-term membrane association (Peitzsch and McLaughlin 1993; McLaughlin and Aderem 1995). The first 16 amino acids of AtCPK5 include a potential palmitoylation site at cysteine-5. Preliminary experiments indicate that Cys-5 is palmitoylated in planta (A. Argyros \& E. Hrabak, unpublished data). Palmitate has about tenfold greater membrane binding affinity than myristate and palmitoylated proteins are invariably membrane associated (Resh 2004). The current model for dual acylation, the kinetic bilayer trapping hypothesis of Shahinian and Silvius (1995), posits that the weak hydrophobicity provided by myristate allows proteins to transiently sample a variety of cellular membranes where specific palmitoyl transferases reside. Conversely, mutation of the myristoylation site prevents transient membrane binding and subsequent cysteine palmitoylation (Degtyarev et al. 1994; Hallak et al. 1994; Wilson and Bourne 1995; Martin and Busconi 2001). Thus, even though wildtype AtCPK5 may be myristoylated and palmitoylated and the palmitoylation site is still present in the G2A mutant, we predicted complete loss of AtCPK5 membrane association when myristoylation was prevented, which is what we observed.

Our results show that AtCPK5 is plasma membrane localized and that the amino terminus of the protein is required for correct localization. Myristoylation of the amino terminal glycine residue of AtCPK5 was critical for membrane binding. The subcellular location of AtCPK5 will be useful for deciphering its substrates and role in plant signal transduction pathways.

Acknowledgments We thank Tracy Lambert for technical assistance in constructing several of the clones used in this study. Partial funding was provided by the New Hampshire Agricultural Experiment Station. This is Scientific Contribution Number 2486.

Open Access This article is distributed under the terms of the Creative Commons Attribution License which permits any use, distribution, and reproduction in any medium, provided the original author(s) and the source are credited.

\section{References}

Abbasi F, Onodera H, Toki S, Tanaka H, Komatsu S (2004) OsCDPK13, a calcium-dependent protein kinase gene from rice, is induced by cold and gibberellin in rice leaf sheath. Plant Mol Biol 55:541-552

Allbritton NL, Meyer T, Stryer L (1992) Range of messenger action of calcium ion and inositol 1,4,5-trisphosphate. Science 258:1812-1815

Alsheimer M, von Galsenapp E, Schnolzer M, Heid H, Benavente R (2000) Meiotic lamin C2: the unique aminoterminal hexapeptide GNAEGR is essential for nuclear envelope association. Proc Natl Acad Sci USA 97:13120-13125
Asano T, Kunieda N, Omura Y, Ibe H, Kawasaki T, Takano M, Sato M, Furuhashi H, Mujin T, Takaiwa F, Wu Cy CY, Tada Y, Satozawa T, Sakamoto M, Shimada H (2002) Rice SPK, a calmodulin-like domain protein kinase, is required for storage product accumulation during seed development: phosphorylation of sucrose synthase is a possible factor. Plant Cell 14:619-628

Asano T, Tanaka N, Yang G, Hayashi N, Komatsu S (2005) Genomewide identification of the rice calcium-dependent protein kinase and its closely related kinase gene families: comprehensive analysis of the CDPKs gene family in rice. Plant Cell Physiol 46:356-366

Baizabal-Aguirre VM, de la Vara LEG (1997) Purification and characterization of a calcium-regulated protein kinase from beet root (Beta vulgaris) plasma membranes. Physiol Plant 99:135-143

Benetka W, Mehlmer N, Maurer-Stroh S, Sammer M, Koranda M, Neumuller R, Betschinger J, Knoblich JA, Teige M, Eisenhaber F (2008) Experimental testing of predicted myristoylation targets involved in asymmetric cell division and calcium-dependent signalling. Cell Cycle 7:3709-3719

Bevan M (1984) Binary Agrobacterium vectors for plant transformation. Nucl Acids Res 12:8711-8721

Boisson B, Giglione C, Meinnel T (2003) Unexpected protein families including cell defense components feature in the $\mathrm{N}$ myristolome of a higher eukaryote. $J$ Biol Chem 278:43418-43429

Bologna G, Yvon C, Duvaud S, Veuthey AL (2004) N-Terminal myristoylation predictions by ensembles of neural networks. Proteomics 4:1626-1632

Chehab EW, Patharkar OR, Hegeman AD, Taybi T, Cushman JC (2004) Autophosphorylation and subcellular localization dynamics of a salt- and water deficit-induced calcium-dependent protein kinase from ice plant. Plant Physiol 135:1430-1446

Cheng S, Willmann MR, Chen H, Sheen J (2002) Calcium signaling through protein kinases. The Arabidopsis calcium-dependent protein kinase gene family. Plant Physiol 129:469-485

Choi HI, Park HJ, Park JH, Kim S, Im MY, Seo HH, Kim YW, Hwang I, Kim SY (2005) Arabidopsis calcium-dependent protein kinase AtCPK32 interacts with ABF4, a transcriptional regulator of abscisic acid-responsive gene expression, and modulates its activity. Plant Physiol 139(4):1750-1761

Clough SJ, Bent AF (1998) Floral dip: a simplified method for Agrobacterium-mediated transformation of Arabidopsis thaliana. Plant J 16:735-743

Coca M, San Segundo B (2010) AtCPK1 calcium-dependent protein kinase mediates pathogen resistance in Arabidopsis. Plant $\mathbf{J}$ 63:526-540

Dammann C, Ichida A, Hong B, Romanowsky S, Hrabak EM, Harmon AC, Pickard BG, Harper JF (2003) Subcellular targeting of nine calcium-dependent protein kinase isoforms from Arabidopsis thaliana. Plant Physiol 132:1840-1848

Davis SJ, Vierstra RD (1998) Soluble, highly fluorescent variants of green fluorescent protein (GFP) for use in higher plants. Plant Mol Biol 36:521-528

DeFalco TA, Bender KW, Snedden WA (2010) Breaking the code: $\mathrm{Ca}^{2+}$ sensors in plant signalling. Biochem $\mathrm{J}$ 425:27-40

Degtyarev MY, Spiegel AM, Jones TLZ (1994) Palmitoylation of a G protein $\mathrm{a}_{\mathrm{i}}$ subunit requires membrane localization not myristoylation. J Biol Chem 269:30898-30903

DeWitt ND, Sussman MR (1995) Immunocytological localization of an epitope-tagged plasma membrane proton pump $\left(\mathrm{H}^{+}\right.$-ATPase $)$ in phloem companion cells. Plant Cell 7:2053-2067

Di Paolo G, Lutjens R, Pellier V, Stimpson SA, Beuchat MH, Catsicas S, Grenningloh G (1997) Targeting of SCG10 to the area of the Golgi complex is mediated by its NH2-terminal region. J Biol Chem 272:5175-5182 
Douglas P, Moorhead G, Hong Y, Morice N, MacKintosh C (1998) Purification of a nitrate reductase kinase from Spinacia oleracea leaves, and its identification as a calmodulin-domain protein kinase. Planta 206:435-442

Dumonceaux T, Rajala RV, Sharma R, Selvaraj G, Datla R (2004) Molecular characterization of a gene encoding $N$-myristoyl transferase (NMT) from Triticum aestivum (bread wheat). Genome 47:1036-1042

Ellard-Ivey M, Hopkins RB, White T, Lomax TL (1999) Cloning, expression and $\mathrm{N}$-terminal myristoylation of $C p C P K 1$, a calcium-dependent protein kinase from zucchini (Cucurbita pepo L.). Plant Mol Biol 39:199-208

Farazi TA, Waksman G, Gordon JI (2001) The biology and enzymology of protein $N$-myristoylation. J Biol Chem 276:39501-39504

Franz S, Ehlert B, Liese A, Kurth J, Cazale A-C, Romeis T (2011) Calcium-dependent protein kinase CPK21 function in abiotic stress response in Arabidopsis thaliana. Mol Plant 4:83-96

Freymark G, Diehl T, Miklis M, Romeis T, Panstruga R (2007) Antagonistic control of powdery mildew host cell entry by barley calcium-dependent protein kinases (CDPKs). Mol Plant Microbe Interact 20:1213-1221

Gallagher SR (1992) Quantitation of GUS activity by fluorometry. In: Gallagher SR (ed) GUS protocols: using the GUS gene as a reporter of gene expression. Academic Press, New York, pp 47-59

Gargantini PR, Gonzalez-Rizzo S, Chinchilla D, Raices M, Giammaria V, Ulloa RM, Frugier F, Crespi MD (2006) A CDPK isoform participates in the regulation of nodule number in Medicago truncatula. Plant J 48:843-856

Geiger D, Scherzer S, Mumm P, Marten I, Ache P, Matschi S, Liese A, Wellmann C, Al-Rasheid KA, Grill E, Romeis T, Hedrich R (2010) Guard cell anion channel SLAC1 is regulated by CDPK protein kinases with distinct $\mathrm{Ca}^{2+}$ affinities. Proc Natl Acad Sci USA 107:8023-8028

Gillen KM, Pausch M, Dohlman HG (1998) N-terminal domain of Gpa1 ( $G$ protein alpha) subunit) is sufficient for plasma membrane targeting in yeast Saccharomyces cerevisiae. J Cell Sci 111:3235-3244

Grebenok RJ, Pierson E, Lambert GM, Gong FC, Afonso CL, Haldeman-Cahill R, Carrington JC, Galbraith DW (1997) Greenfluorescent protein fusions for efficient characterization of nuclear targeting. Plant J 11:573-586

Hakes DJ, Dixon JE (1992) New vectors for high level expression of recombinant proteins in bacteria. Anal Biochem 202:293-298

Hallak H, Brass LF, Manning DR (1994) Failure to myristoylate the a subunit of $\mathrm{Gz}$ is correlated with inhibition of palmitoylation and membrane attachment, but has no affect on phosphorylation of protein kinase C. J Biol Chem 269:4571-4576

Harper JF, Breton G, Harmon A (2004) Decoding $\mathrm{Ca}(2+)$ signals through plant protein kinases. Annu Rev Plant Biol 55:263-288

Hashimoto K, Kudla J (2011) Calcium decoding mechanisms in plants. Biochem 93:2054-2059

Hegeman AD, Rodriguez M, Han BW, Uno Y, Phillips GN Jr, Hrabak EM, Cushman JC, Harper JF, Harmon AC, Sussman MR (2006) A phyloproteomic characterization of in vitro autophosphorylation in calcium-dependent protein kinases. Proteomics 6:3649-3664

Hofte H, Hubbard L, Reizer J, Ludevid D, Herman EM, Chrispeels MJ (1992) Vegetative and seed-specific forms of tonoplast intrinsic protein in the vacuolar membrane of Arabidopsis thaliana. Plant Physiol 99:561-570

Hrabak EM, Dickmann LJ, Satterlee JS, Sussman MR (1996) Characterization of eight new members of the calmodulin-like domain protein kinase gene family of Arabidopsis thaliana. Plant Mol Biol 31:405-412
Hrabak EM, Chan CCW, Gribskov M, Harper JF, Choi JH, Halford N, Kudla J, Luan S, Nimmo HG, Sussman MR, Thomas M, Walker-Simmons K, Zhu J-K, Harmon AC (2003) The Arabidopsis CDPK-SnRK superfamily of protein kinases. Plant Physiol 132:666-680

Huang J-F, Teyton L, Harper JF (1996) Activation of a $\mathrm{Ca}^{2+}$-dependent protein kinase involves intramolecular binding of a calmodulinlike regulatory domain. Biochemistry 35:13222-13230

Ishitani M, Liu J, Halfter U, Kim C-S, Shi W, Zhu J-K (2000) SOS3 function in plant salt tolerance requires $N$-myristoylation and calcium binding. Plant Cell 12:1667-1677

Ito T, Nakata M, Fukazawa J, Ishida S, Takahashi Y (2010) Alteration of substrate specificity: the variable $\mathrm{N}$-terminal domain of tobacco $\mathrm{Ca}^{2+}$-dependent protein kinase is important for substrate recognition. Plant Cell 22:1592-1604

Ivashuta S, Liu J, Liu J, Lohar DP, Haridas S, Bucciarelli B, VandenBosch KA, Vance CP, Harrison MJ, Gantt JS (2005) RNA interference identifies a calcium-dependent protein kinase involved in Medicago truncatula root development. Plant Cell 17:2911-2921

Iwata Y, Kuriyama M, Nakakita M, Kojima H, Ohto M, Nakamura K (1998) Characterization of a calcium-dependent protein kinase of tobacco leaves that is associated with the plasma membrane and is inducible by sucrose. Plant Cell Physiol 39:1176-1183

Johnson DR, Bhatnagar RS, Knoll LJ, Gordon JI (1994) Genetic and biochemical studies of protein $N$-myristoylation. Annu Rev Biochem 63:869-914

Katiyar-Agarwal S, Zhu J, Kim K, Agarwal M, Fu X, Huang A, Zhu JK (2006) The plasma membrane $\mathrm{Na}^{+} / \mathrm{H}+$ antiporter SOS 1 interacts with RCD1 and functions in oxidative stress tolerance in Arabidopsis. Proc Natl Acad Sci USA 103:18816-18821

Klimecka M, Muszynska G (2007) Structure and functions of plant calcium-dependent protein kinases. Acta Biochim Pol 54:219-233

Klimyuk VI, Carroll BJ, Thomas CM, Jones JDG (1993) Alkali treatment for rapid preparation of plant material for reliable PCR analysis. Plant J 3:493-494

Kobayashi M, Ohura I, Kawakita K, Yokota N, Fujiwara M, Shimamoto K, Doke N, Yoshioka H (2007) Calcium-dependent protein kinases regulate the production of reactive oxygen species by potato NADPH oxidase. Plant Cell 19:1065-1080

Kobayashi M, Yoshioka M, Asai S, Nomura H, Kuchimura K, Mori H, Doke N, Yoshioka H (2012) StCDPK5 confers resistance to late blight pathogen but increases susceptibility to early blight pathogen in potato via reactive oxygen species burst. New Phytol 196:223-237

Kudla J, Batistic O, Hashimoto K (2010) Calcium signals: the lead currency of plant information processing. Plant Cell 22:541-563

Larsson C, Widell S, Kjellbom P (1987) Preparation of high-purity plasma membranes. Methods Enzymol 148:558-568

Li J, Lee Y-RJ, Assmann SM (1998) Guard cells possess a calciumdependent protein kinase that phosphorylates the KAT1 potassium channel. Plant Physiol 116:785-795

Li Y, Gou M, Hua J (2010) Requirement of calcium binding, myristoylation, and protein-protein interaction for the copine BON1 function in Arabidopsis. J Biol Chem 285:29884-29891

Lichtenthaler HK (1987) Chlorophylls and carotenoids: pigments of photsynthetic membranes. Methods Enzymol 148:350-382

Lodge JK, Johnson RL, Weinberg RA, Gordon JI (1994) Comparison of myristoyl-CoA:protein $N$-myristoyl transferases from three pathogenic fungi: Cryptococcus neoformans, Histoplasma capsulatum, and Candida albicans. J Biol Chem 269:2996-3009

Lu SX, Hrabak EM (2002) An Arabidopsis calcium-dependent protein kinase is associated with the endoplasmic reticulum. Plant Physiol 128:1008-1021

Ludwig AA, Saitoh H, Felix G, Freymark G, Miersch O, Wasternack C, Boller T, Jones JD, Romeis T (2005) Ethylene-mediated 
cross-talk between calcium-dependent protein kinase and MAPK signaling controls stress responses in plants. Proc Natl Acad Sci USA 102:10736-10741

Luethy MH, Horak A, Elthon TE (1993) Monoclonal antibodies to the [alpha]- and [beta]-subunits of the plant mitochondrial $F_{1}$-ATPase. Plant Physiol 101:931-937

Ma SY, Wu WH (2007) AtCPK23 functions in Arabidopsis responses to drought and salt stresses. Plant Mol Biol 65:511-518

Martin ML, Busconi L (2000) Membrane localization of a rice calcium-dependent protein kinase (CDPK) is mediated by myristoylation and palmitoylation. Plant J 24:429-435

Martin ML, Busconi L (2001) A rice membrane-bound calciumdependent protein kinase is activated in response to low temperature. Plant Physiol 125:1442-1449

Maurer-Stroh S, Eisenhaber B, Eisenhaber F (2002a) N-terminal $N$-myristoylation of proteins: prediction of substrate proteins from amino acid sequence. J Mol Biol 317:541-557

Maurer-Stroh S, Eisenhaber B, Eisenhaber F (2002b) N-terminal $\mathrm{N}$-myristoylation of proteins: refinement of the sequence motif and its taxon-specific differences. J Mol Biol 317:523-540

Maurer-Stroh S, Gouda M, Novatchkova M, Schleiffer A, Schneider G, Sirota FL, Wildpaner M, Hayashi N, Eisenhaber F (2004) MYRbase: analysis of genome-wide glycine myristoylation enlarges the functional spectrum of eukaryotic myristoylated proteins. Genome Biol 5:R21

McLaughlin S, Aderem A (1995) The myristoyl-electrostatic switch: a modulator of reversible protein-membrane interactions. Trends Biochem Sci 20:272-276

Mehlmer N, Wurzinger B, Stael S, Hofmann-Rodrigues D, Csaszar E, Pfister B, Bayer R, Teige M (2010) The $\mathrm{Ca}^{2+}$-dependent protein kinase CPK3 is required for MAPK-independent salt-stress acclimation in Arabidopsis. Plant J 63:484-498

Mori IC, Murata Y, Yang Y, Munemasa S, Wang YF, Andreoli S, Tiriac H, Alonso JM, Harper JF, Ecker JR, Kwak JM, Schroeder JI (2006) CDPKs CPK6 and CPK3 function in ABA regulation of guard cell S-type anion- and $\mathrm{Ca}^{2+}$-permeable channels and stomatal closure. PLoS Biol 4:e327

Peck SC (2006) Analysis of protein phosphorylation: methods and strategies for studying kinases and substrates. Plant J 45:512-522

Pei ZM, Ward JM, Harper JF, Schroeder JI (1996) A novel chloride channel in Vicia faba guard cell vacuoles activated by the serine/ threonine kinase, CDPK. EMBO J 15:6564-6574

Peitzsch RM, McLaughlin S (1993) Binding of acylated peptides and fatty acids to phospholipid vesicles: pertinence to myristoylated proteins. Biochemistry 32:10436-10443

Pierre M, Traverso JA, Boisson B, Domenichini S, Bouchez D, Giglione C, Meinnel T (2007) N-Myristoylation regulates the SnRK1 pathway in Arabidopsis. Plant Cell 19:2804-2821

Podell S, Gribskov M (2004) Predicting N-terminal myristoylation sites in plant proteins. BMC Genomics 5:37

Qi Q, Rajala RVS, Anderson W, Jiang C, Rozwadowski K, Selvaraj G, Sharma R, Datla R (2000) Molecular cloning, genomic organization, and biochemical characterization of myristoylCoA:protein $N$-myristoyltransferase from Arabidopsis thaliana. J Biol Chem 275:9673-9683

Raices M, Chico JM, Telez-Inon MT, Ulloa RM (2001) Molecular characterization of StCDPK1, a calcium-dependent protein kinase from Solanum tuberosum that is induced at the onset of tuber development. Plant Mol Biol 46:591-601

Raices M, Gargantini PR, Chinchilla D, Crespi M, Tellez-Inon MT, Ulloa RM (2003) Regulation of CDPK isoforms during tuber development. Plant Mol Biol 52:1011-1024

Rajala RV, Datla RS, Moyana TN, Kakkar R, Carlsen SA, Sharma RK (2000) $N$-myristoyltransferase. Mol Cell Biochem 204:135-155
Raju RVS, Magnuson BA, Sharma RK (1995) Mammalian myristoyl CoA:protein $N$-myristoyltransferase. Mol Cell Biochem 149(150):191-202

Resh MD (2004) Membrane targeting of lipid modified signal transduction proteins. Subcell Biochem 37:217-232

Rocque WJ, McWherter CA, Wood DC, Gordon JI (1993) A comparative analysis of the kinetic mechanism and peptide substrate specificity of human and Saccharomyces cerevisiae myristoyl-CoA:protein $N$-myristoyltransferase. J Biol Chem 268:9964-9971

Rodriguez Milla MA, Uno Y, Chang IF, Townsend J, Maher EA, Quilici D, Cushman JC (2006) A novel yeast two-hybrid approach to identify CDPK substrates: characterization of the interaction between AtCPK11 and AtDi19, a nuclear zinc finger protein. FEBS Lett 580:904-911

Romeis T, Piedras P, Jones JDG (2000) Resistance gene-dependent activation of a calcium-dependent protein kinase in the plant defense response. Plant Cell 12:803-815

Romeis T, Ludwig AA, Martin R, Jones JDG (2001) Calciumdependent protein kinases play an essential role in a plant defence response. EMBO J 20:5556-5567

Rutschmann F, Stalder U, Piotrowski M, Oecking C, Schaller A (2002) LeCPK1, a calcium-dependent protein kinase from tomato. Plasma membrane targeting and biochemical characterization. Plant Physiol 129:156-168

Schaller GE, DeWitt ND (1995) Analysis of the $\mathrm{H}^{+}$-ATPase and other proteins of the Arabidopsis plasma membrane. Methods Cell Biol 50:129-148

Schaller GE, Harmon AC, Sussman MR (1992) Characterization of a calcium- and lipid-dependent protein kinase associated with the plasma membrane of oat. Biochemistry 31:1721-1727

Shahinian S, Silvius JR (1995) Doubly-lipid-modified protein sequence motifs exhibit long-lived anchorage to lipid bilayer membranes. Biochemistry 34:3813-3822

Szczegielniak J, Klimecka M, Liwosz A, Ciesielski A, Kaczanowski S, Dobrowolska G, Harmon AC, Muszynska G (2005) A woundresponsive and phospholipid-regulated maize calcium-dependent protein kinase. Plant Physiol 139:1970-1983

Towler DA, Adams SP, Eubanks SR, Towery DS, Jackson-Machelski E, Gordon JI (1988) Myristoyl CoA:protein $N$-myristoyltransferase activities from rat liver and yeast possess overlapping yet distinct peptide substrate specificities. J Biol Chem 263:1784-1790

Utsumi T, Nakano K, Funakoshi T, Kayano Y, Nakao S, Sakurai N, Iwata H, Ishisaka R (2004) Vertical-scanning mutagenesis of amino acids in a model $\mathrm{N}$-myristoylation motif reveals the major amino-terminal sequence requirements for protein $\mathrm{N}$-myristoylation. Eur J Biochem 271:863-874

Verhey SD, Gaiser JC, Lomax TL (1993) Protein kinases in zucchini. Characterization of calcium-requiring plasma membrane kinases. Plant Physiol 103:413-419

Wilson PT, Bourne HR (1995) Fatty acylation of $a_{z}$. Effects of palmitoylation and myristoylation on $\mathrm{a}_{\mathrm{z}}$ signaling. J Biol Chem 270:9667-9675

Witte CP, Keinath N, Dubiella U, Demouliere R, Seal A, Romeis T (2010) Tobacco calcium-dependent protein kinases are differentially phosphorylated in vivo as part of a kinase cascade that regulates stress response. J Biol Chem 285:9740-9748

Ye S, Wang L, Xie W, Wan B, Li X, Lin Y (2009) Expression profile of calcium-dependent protein kinase (CDPKs) genes during the whole lifespan and under phytohormone treatment conditions in rice (Oryza sativa L. ssp. indica). Plant Mol Biol 70:311-325

Yoon GM, Dowd PE, Gilroy S, McCubbin AG (2006) Calciumdependent protein kinase isoforms in Petunia have distinct functions in pollen tube growth, including regulating polarity. Plant Cell 18:867-878 
Zhang XS, Choi JH (2001) Molecular evolution of calmodulin-like domain protein kinases (CDPKs) in plants and protists. J Mol Evol 53:214-224

Zhu SY, Yu XC, Wang XJ, Zhao R, Li Y, Fan RC, Shang Y, Du SY, Wang XF, Wu FQ, Xu YH, Zhang XY, Zhang DP (2007) Two calcium-dependent protein kinases, CPK4 and CPK11, regulate abscisic acid signal transduction in Arabidopsis. Plant Cell 19:3019-3036 